Discourse and Communication for Sustainable Education, vol. 10, no. 2, pp. 5-12, 2019

\title{
Entrepreneurial Spirit for the Whole School - Ways to Become an e.e.si-Entrepreneurship School
}

\author{
Johannes Lindner \\ University Teacher College, Vienna/Krems, Austria
}

\begin{abstract}
All entrepreneurs of the future are at school today, the nature of their value-oriented education and their willingness to actively participate in business and society in the future is shaped by today's learning. This article focuses on the development, the reasoning, the legal bases, the implementation and the future perspectives of the Austrian approach to Entrepreneurship Education with a specific focus on an Entrepreneurship School Certification. Entrepreneurship Education in schools involves a variety of factors: the learning program, the learning environment, the teachers with their passion, encouragement and appreciation of learners and the value-orientation of the organization, which ranges from corporate culture to networking with external school partners.
\end{abstract}

Key words: entrepreneurship education, entrepreneurial challenge-based learning, e.e.si, entre school, the Trio model for entrepreneurship education, sustainable entrepreneurial design.

\section{Introduction}

Entrepreneurially and socially proactive people are of central importance for the development of the society and the economy. Proactive citizens do not 'fall from the sky'. Without the dreams of visionaries and people who put ideas actively into practice we would live in a different world nowadays. We need entrepreneurial thinking everywhere. Entrepreneurship is a mental mindset, where people actively participate in society in such a way that they firstly identify what must be done to be able to work out a solution afterwards. An entrepreneurial mindset has to be learned - in fact from generation to generation anew. Each generation is once again challenged to develop these entrepreneurial competences, ideas and values which are important for people's lives and the society. The development of the entrepreneurial mindset needs entrepreneurial learning and an environment that strengthens and encourages entrepreneurship (TWG, 2014).

This article is a plea for strengthening entrepreneurship education for young people. In the course of time, an overall concept for an 'Entrepreneurship School' should develop from various individual activities at a school. This is based on the conviction that Entrepreneurship Education and school development must go hand in hand and involve all those engaged in everyday school life in order to facilitate long-term changes. The article 
is based on several years of experience in the development and implementation of an outcome-oriented Entrepreneurship School approach by the e.e.si Centre for Entrepreneurship Education in Austria.

This article answers the follows questions:

1. What is Entrepreneurship Education?

2. How can an 'Entrepreneurship School (EntreSchool)' be organised?

\section{Clarifying the Terms}

Even though the terms 'entrepreneur' and 'entrepreneurship' are not yet commonly used in German-speaking countries - unlike other English business terms such as 'management' or 'marketing' - they have become more widely known in recent years. The terms have derived from the French word 'entreprendre' ('to undertake'/'to launch'). In their current meaning they were introduced by Joseph Schumpeter (1911). Entrepreneurs are independent protagonists. According to Schumpeter (1911) they are the key drivers of economic and social dynamics. Schumpeter emphasized their skills and abilities for the independent development and implementation of ideas and stressed their innovative power, which encompasses the creation of new products, production processes, organizational structures or alternative distribution channels. Entrepreneurs play a relevant role in all parts of our society: from business, religion, sciences and politics to education and sports. Generally speaking, anybody can become active as an entrepreneur (Faltin, 2013). The terms 'intrapreneurs' and 'co-entrepreneurs' (Pinchot, 1984; Wunderer, 1999) describe entrepreneurs who are not self-employed, but decide to become entrepreneurially active within a company. 'Social entrepreneurs' or 'change-makers' (Drayton, 2003) are individuals who combine entrepreneurial and social initiatives to bring about a positive change in society. They implement ideas in areas such as education, environmental protection or the creation of jobs for persons with disabilities.

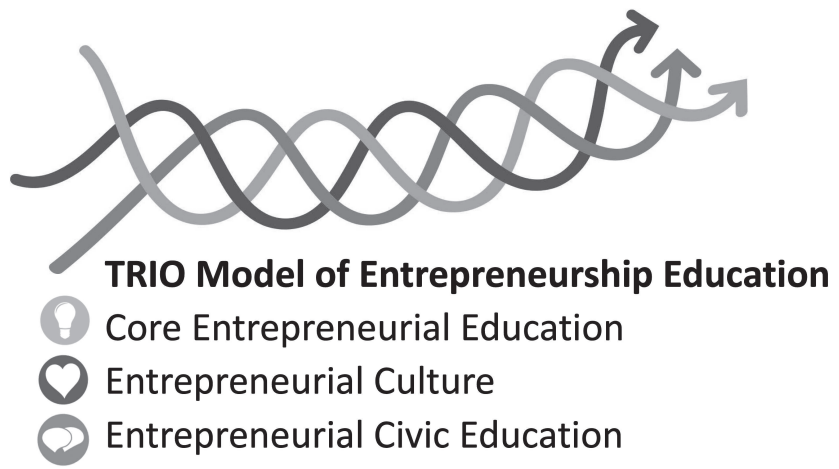

Figure 1. TRIO Model of entrepreneurship education (author's graphic)

The term 'Entrepreneurship Education' refers to the development of independent ideas and the acquisition of the respective skills and abilities that are necessary to implement these ideas. Emancipatory approaches to entrepreneurship education emphasize its social and pedagogical relevance for society (Lindner, 2009; Lindner, 2018). The TRIO Model of Entrepreneurship Education offers a good overview of the most important 
interlinked segments of Entrepreneurship Education (see Figure 1): Segment I, Core Entrepreneurship Education, teaches core competences that foster entrepreneurial and professional independence and support independent decisions for one's private life. Segment II, entrepreneurial culture, focuses on the promotion of a culture of independence, passion, inspiration, open-mindedness, empathy and sustainability that encourages relationships and communication. Segment III, Entrepreneurial Civic Education, aims at promoting a culture of autonomy and responsibility to face social challenges. This is achieved through the development and support of ideas for social initiatives and a personal commitment to their implementation (Aff and Lindner, 2005). To refer to the Austrian approach to Entrepreneurship Education in general and to the Entrepreneurship School Certification in particular the author would like to introduce the term 'EntreSchool'. This abbreviation summarizes all the ideas, criteria and necessary measures described in this article.

\section{Entrepreneurial Spirit Should Cover the Whole School}

The starting point for the development of an Entrepreneurship Education school concept was at an Austrian school and dates back to 1999. The 'Entrepreneurship Education and Talent Promotion' school experiment was tested at a Viennese Business College with modules across all subjects and scientifically accompanied over seven years (Lindner, 2005). After a pilot phase, parts of the concept were included in the regular Business College curriculum and the 'Schumpeter Business College Model' has since been an integral part of the Viennese educational offer.

The further development of Entrepreneurship Education took place as a mixture of a bottom-up approach (by pioneer teachers) and the support of the school authorities. The 'e.e.si-Media Package Entrepreneurship' (Aff et al., 2004) was developed to support the implementation of Entrepreneurship Education in various subjects (transversal skills) and the curricular edition 'Entrepreneur' (Lindner et al., 2005) was launched by the Initiative for Teaching Entrepreneurship Association.

The Ministry of Education, Science and Research supported the activities by establishing the e.e.si-Impulse Centre for Entrepreneurship Education in 2006. Federal and state coordinators for Entrepreneurship Education were appointed. The basic principles of the Viennese pilot project were critically evaluated, further developed and adapted to the conditions at other school locations.

In the course of time, various individual activities within the framework of Entrepreneurship Education have developed into an overall concept for the certification of entire schools. This procedure is based on the conviction that Entrepreneurship Education and school development go hand in hand and must involve all persons engaged in everyday school life in order to make sustainable changes possible. The e.e.si 'Entrepreneurship School (EntreSchool)' approach comprises Business Schools and Colleges as well as Colleges of Social and Services Industries and has been opened to further types of schools.

\section{But What are the Special Features of an Entrepreneurship School (EntreSchool)?}

In an Entrepreneurship School (EntreSchool), measures to foster entrepreneurial thinking, personality development and the education to be a responsible citizen are integrative parts of teaching and of everyday school life. 'Entrepreneurial Spirit' is promoted 
by the organization of the school. Promoting the students' personal competences and achievement potentials regarding entrepreneurial, independent and autonomous acting, intensifying communicative competences as well as creating suitable communication structures between school administration, teachers, students and parents must not be neglected when planning a coherent Entrepreneurship School (EntreSchool) program.

Based on the priorities of the European Union, the Austrian Federal Ministry of Education, Science and Research and the Austrian Federal Boards of Education - all these institutions consider Entrepreneurship Education as a particularly important part of a good education and training at school - the certification 'Entrepreneurship School (EntreSchool)' aims at approving the individual school officially to have successfully implemented entrepreneurship activities in a holistic and target-oriented way as well as on a long-term basis. Sustainable Entrepreneurship Education is only possible when it is an integral part of the school development process and when it is born and lived by all the people involved in school life. Learning and teaching must be 'entrepreneurially' planned and organized. Main emphases of the certification are put on the activities at school, the basics for teachers as well as the organizational structures.

For this purpose, a catalogue of criteria (e.e.si, 2019 and Figure 2) was developed by the members of the e.e.si-Impulse Centre for Entrepreneurship Education of the Ministry of Education, Science and Research together with a team of committed teachers from all federal states. This has resulted in the Austrian Standards Institute's ON Guideline No. 42001', which sets standards beyond the school sector. Based on the 'Trio Model of Entrepreneurship Education,' activities in an Entrepreneurship School (EntreSchool) - from the development of own business ideas, the promotion of entrepreneurial thinking and personality development to the education to become mature citizens - are integral parts of teaching and everyday school life in all subjects taught.

After the decision to strive for certification has been made at a school location, the individual support of the school is provided by the e.e.si team in order to implement the criteria from the handbook provided (e.e.si, 2019). It is possible to aim for the 'Basic' or 'Advanced' level and, as a school, to select the criteria from a catalogue that includes compulsory and optional criteria that best correspond to the school profile.

The areas of the criteria catalogue are:

- activities at school,

- basics for teachers, and

- the organisational framework.

The e.e.si-Entrepreneurship School (EntreSchool) approach is outcome-oriented, i.e. the process and the results are reviewed during the certification process. The evidence required for certification is provided by submitting documentation on the school's activities over a period of approximately one and a half years. The first certification was awarded to the Schumpeter Business College in November 2012. In the period 2013-2015, further 28 school locations followed - one of them is the Meran Business College, which has established itself as a pioneering school in South Tyrol. Expressed in numbers, the Entrepreneurship School (EntreSchool) program reached about 10,000 students every year in the period 2013-2015. In the period 2016-2018, the number of certified schools reached 60 and involving about 20,000 students every year. 


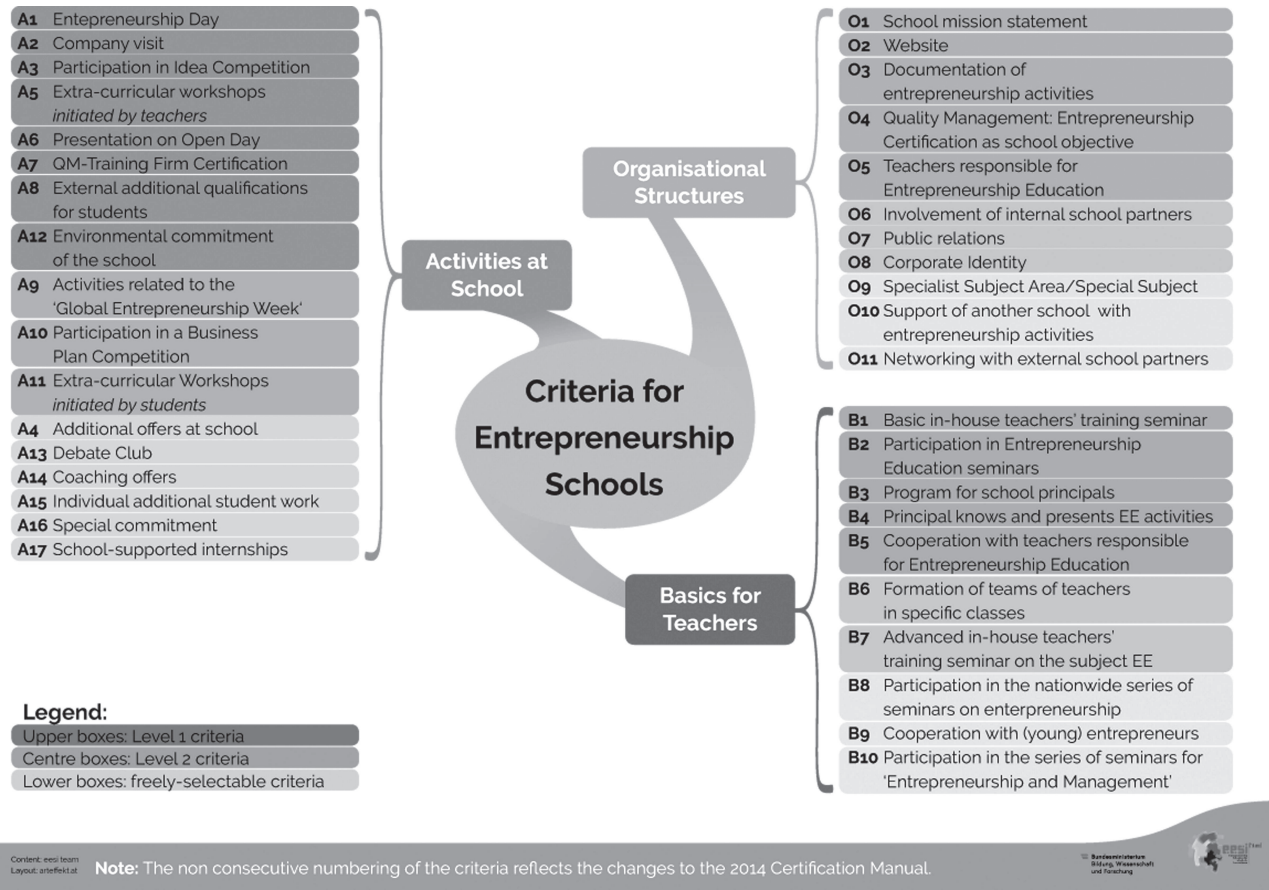

Figure 2. Criteria for Entrepreneurship Schools (EntreSchools) (e.e.si, 2019)

The certificates (see Figure 3) are valid for two years. Schools that have already achieved 'Basic' certification have the opportunity to aim for the 'Advanced' level in the next two years. Locations that are already certified on the 'advanced' level can register for further certification.

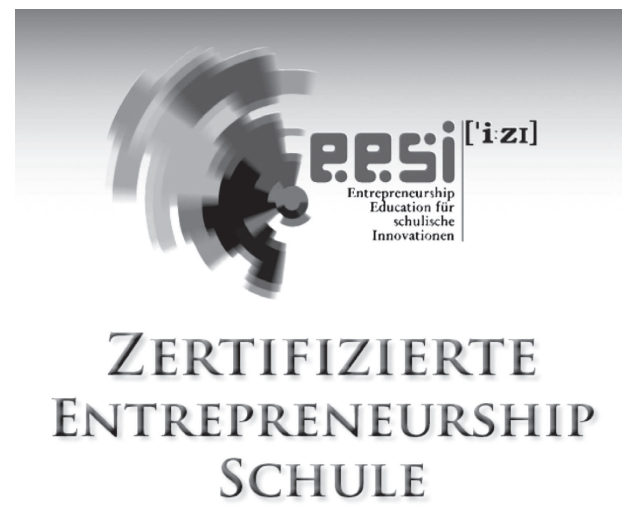

Figure 3. Certificate for Entrepreneurship Schools (EntreSchools) (e.e.si, 2019)

With the 'Entrepreneurship School (EntreSchool)' certification process as the recognized ON guideline no. 42001 of the Austrian Standards Institute, Austria is a pioneer in the consolidation of innovative Entrepreneurship Education in the course of school development. 
Some Positive Aspects of this Certification Process are as following:

- From pioneer teachers to a team of teachers: Entrepreneurship Education at a school location usually goes back to a few pioneer teachers, with the certification process a large number of the teachers are involved.

- From a lone fighter to a team player: The discussion of the entrepreneurship certification criteria make it clear what is already happening at a school location, how many different activities already exist; the goal - the achievement of the certification - is only possible through the interaction and participation of everybody involved in school life.

- Bottom-up approach: A very positive aspect is that the Entrepreneurial Spirit is carried from one school to the next.

- Structure supported by the certification process: The structure of the certification process makes Entrepreneurship Education tangible for many teachers.

- Autonomy of the school: The certification process supports the autonomy of the school, as different school-specific ways of Entrepreneurship Education can be developed.

- Involvement of general education and vocational training: With the TRIO model of Entrepreneurship Education, teachers of general subjects succeed in becoming involved, especially at levels 2 and 3 .

- Longer-term anchoring: It is ensured that students are taught to think and act entrepreneurially, regardless of which class or year they are in.

- Outcome-oriented Entrepreneurship School approach: Results are achieved in many classes, thus enabling many students to be systematically involved. Entrepreneurship Education thus becomes a regular part of the compulsory education offered by the school.

- Celebration culture: Entrepreneurship Schools organize cross-class events within schools (Idea-Festivals) and take part in cross-school competitions (Idea Competition etc.). The students' successes are celebrated in a similar way as in sports.

- Strengthening school culture: The highlight of the certification process for an entire school is the ceremonial presentation of the certificates at the Entrepreneurship Summit in Vienna. What has been achieved makes the team proud and strengthens the motivation to continue.

Much has already happened on the way to implement Entrepreneurship Education and much still lies ahead. The positioning of the teaching principle and the entrepreneurship competences in the syllabus of the Business Colleges 2014 and other school types have contributed a great deal to strengthen the idea. In the next generation of syllabuses 2020/2021 the position of Entrepreneurship Education will be further reinforced. The National Action Plan for Entrepreneurship Education (Kiss \& Lindner, 2019) will additionally support the systematic implementation on all competence levels (from elementary to secondary level).

Austria contributes its positive experience in the field of Entrepreneurship Education by having had the methodological lead in the Policy Experimentation Project "Youth Start Entrepreneurial Challenges" - funded by the EU within the framework of Key Action 3 (Lindner, 2015)2. The further development of the e.e.si-Entrepreneurship School (EntreSchool) Approach 2019/2020 will bring a stronger link with "Youth Start” entrepreneurial challenge-based learning (Jambor \& Lindner, 2019) and an expansion to other school types (Kiss \& Lindner, 2019). 


\section{Conclusion}

The idea of an Entrepreneurship School (EntreSchool) is to consider Entrepreneurship Education as part of all subjects, not as a separated concept. It comprises learning activities in all study areas and school cultures and is always result-oriented. In an Entrepreneurship School, measures to promote entrepreneurial and sustainable thinking, personality development and the education of responsible citizens are integral parts of teaching and everyday school life. Entrepreneurship is promoted by the design of the school. Entrepreneurship Education and school development should go hand in hand and involve all persons engaged in everyday school life in order to make sustainable changes possible.

The promotion of personal competences and performance potentials of the pupils with regard to entrepreneurial, sustainable, self-responsible and self-determined action, the deepening of communicative competences as well as the creation of suitable communication structures between school management, teachers, pupils and parents must not be ignored when planning a coherent Entrepreneurship School programme.

The Entrepreneurship School certification aims to at confirming to a school location that entrepreneurship activities have been implemented holistically, in a goal-oriented way and on a long-term basis in everyday school life. Students achieve remarkable learning outcomes. Sustainable Entrepreneurship Education is only possible if it is integrated into the school development process and is supported and lived by all those involved in the school. Learning and teaching must be planned and designed in the spirit of the "sustainable entrepreneurial spirit".

The objective of all efforts is to give young people a good start in life. The principles of Entrepreneurship Education have been proven to help, 'Encourage students to take their lives into their own hands as far as possible'. Students should become co-creators of their own lives and of society - in a changing world (Aff \& Lindner, 2005).

\section{Notes:}

(1) $2019 / 2020$ the outcome-oriented certification process will be elaborated, and a new Austrian Standards Institute number will be assigned.

(2) Within the framework of the field test, entrepreneurship competences are promoted across disciplines and learning and teaching arrangements are tested. Learners should develop and implement ideas for 'challenges from the reality of life'. The field trial was conducted between 2015-2018 in a Cooperation of Ministries of Education in Austria, Luxembourg, Portugal, Slovenia and bilaterally in Bulgaria and covered all competence levels (i.e. elementary, lower secondary and upper secondary). Details: www.youthstart.eu.

\section{References}

Aff, J. et al. (2004). e.e.si-Unterrichtskoffer Entrepreneurship [e.e.si media package Entrepreneurship]. Vienna: Manz.

Aff, J., \& Lindner, J. (2005). Entrepreneurship Education zwischen 'small and big ideas' Markierungen einer Entrepreneurship Education an wirtschaftsberuflichen Vollzeitschulen [Entrepreneurship Education between 'small and big ideas' - marks of Entrepreneurship Education at full-time business schools]. In Aff, J., \& Hahn, A. (Eds.). 
Entrepreneurship-Erziehung und Begabungsförderung an wirtschaftsberuflichen Vollzeitschulen. [Entrepreneurship Education and talent promotion at full-time business schools]. (pp. 83-138). Innsbruck: StudienVerlag.

Drayton, B. (2003). Ashoka's theory of change. Arlongton: Ashoka Foundation.

e.e.si (2019). Entrepreneurship school - certification catalogue, entrepreneurship education as school innovation (e.e.si). Impulse Centre of the Austrian Ministry of Education, Science and Research. Vienna: e.e.si.

Faltin, G. (2013). Brains versus capital. Entrepreneurship for everyone lean, smart, simple. Berlin: Entrepreneurship Foundation.

Jambor, E., \& Lindner, J. (2019). You ${ }^{\text {th }}$ start entrepreneurial challenges, materials for teachers and students. Retrieved from www.youthstart.eu

Kiss, K., \& Lindner, J. (2019). Nationaler Aktionsplan für Entrepreneurship Educationvon der Elementarstufe bis zur Sekundarstufe [National Action Plan for Entrepreneurship Education - from elementary to secondary level]. Working Paper. Vienna: Austrian Ministry of Education, Science and Research.

Lindner, J. et al. (2005). Entrpreneur: Menschen, die Ideen umsetzen [People who implement ideas]. Vienna: IFTE.

Lindner, J. (2009). Entrepreneurship Education zwischen ökonomischer Ausbildungsphilosophie und Schlüsselkompetenz für das lebenslange Lernen [Entrepreneurship Education between economic education philosophy and key competence for lifelong learning]. In Stock, M. (Ed.). Entrepreneurship - Europa als Bildungsraum - Europäischer Qualifikationsrahmen [Entrepreneurship - Europe as an educational area European Qualifications Framework]. Vienna: Manz.

Lindner, J. (2015). Entrepreneurship Education für Jugendliche [Youth entrepreneurship education]. GW-Unterricht [Journal for Geography and Economic Instruction], 140(4), 39-49.

Lindner, J. (2018). Entrepreneurship education for a sustainable future. Discourse and Communication for Sustainable Education, 9(1), 115-127.

Pinchot, G. (1984). Who is the Entrepreneur? Intrapreneuring: Why you don't have to leave the corporation to become an entrepreneur. New York.

Schumpeter, J. A. [1911]. (2008). The theory of economic development: An inquiry into profits, capital, credit, interest and the business cycle. USA and London New Brunswic: Transaction Publishers.

TWG (2014). Thematic working group on Entrepreneurship Education of the European Commission: Final report. Brussels: European Commission.

Wunderer, R. (1999). Mitarbeiter als Mitunternehmer - ein Transformationskonzept [Employees as co-entrepreneurs - a transformation concept]. In Wunderer, R. (Ed.). Mitarbeiter als Mitunternehmer [Employees as co-entrepreneurs]. (pp. 22-58). Neuwied: Hermann Luchterhand.

Correspondence relating to this paper should be addressed to Johannes Lindner, University Teacher College, Vienna/Krems, founder of the Initiative for Teaching Entrepreneurship (IFTE) and the e.e.si-Centre for Entrepreneurship Education for school innovation of the Austrian Federal Ministry of Education, Science and Research, Schumpeter College, Ashoka Fellow. Email: johannes.lindner@kphvie.ac.at 